\title{
Review of the Transgender Literature: Where Do We Go from Here?
}

\author{
Jonathon W. Wanta ${ }^{1, *}$ and Cecile A. Unger ${ }^{2}$
}

\begin{abstract}
Purpose: The "transgender tipping point" has brought transgender social and health issues to the forefront of American culture. However, medical professionals have been lagging in academic research with a transgenderspecific focus resulting in significant knowledge gaps in dealing with the care of our transgender patients The aim of this article is to analyze all published Medline-available transgender-specific articles, identify these knowledge gaps, and direct future research to where it is most needed.

Methods: We surveyed all Medline-available articles up to June 2016 using a combination of medical subject headings and keywords in titles and abstracts. Articles meeting inclusion criteria were reviewed, categorized, and analyzed for content and study design.

Results: In our review of the literature, we identified 2405 articles published from January 1950 to June 2016 that focused on transgender health, primarily in the fields of surgery, mental health, and endocrinology.

Conclusion: Significant knowledge gaps were found across the subspecialties, and there was a lack of prospective robust research and representation of transgender-specific data in the core medical journals. More data and research are needed to bridge the knowledge gaps that currently exist and improve the care of the transgender community.
\end{abstract}

Keywords: gender dysphoria; gender identity disorder; review; transgender; transsexual

\section{Introduction}

Transgender care is at the forefront of American conversation. Celebrities like Laverne Cox and Caitlyn Jenner have become household names, promoting transgender visibility and acceptance. The current revolution in society and ideology represents what has been labeled the "transgender tipping point."

To accommodate the growing number of transgender individuals seeking medical care, multidisciplinary care centers across the United States have been developed at institutions like the Cleveland Clinic, New York University, University of California-San Francisco, Mount Sinai Hospital, and Boston Medical Center. Such teams are important for the coordination of care and typically include adult and adolescent mental health providers, endocrinologists, gynecologists, and surgeons.
These advances in medical care have been met with an equal, but opposite force of stigma and discrimination. In a 2011 report from the National Center for Transgender Equality and the National Gay and Lesbian Task Force, $78 \%$ of transgender respondents had experienced verbal harassment and $35 \%$ had experienced physical assault. ${ }^{2}$ Most recently, lawmakers have waged war over bathroom usage in North Carolina with House Bill 2, drawing national criticism and media attention. ${ }^{3}$ Discrimination unfortunately extends beyond the bathroom, even into our own medical practices. By one survey, $28 \%$ of transgender individuals report having experienced harassment in a medical setting and 19\% report having been refused care due to their gender identity. ${ }^{2}$

While we would like to think that progress has been made since that report was published, there is a paucity

\footnotetext{
${ }^{1}$ School of Medicine, Case Western Reserve University, Cleveland, Ohio.

${ }^{2}$ Center for Urogynecology and Pelvic Reconstructive Surgery, Obstetrics, Gynecology \& Women's Health Institute, Cleveland Clinic, Cleveland, Ohio.

*Address correspondence to: Jonathon W. Wanta, BA, School of Medicine, Case Western Reserve University, 2109 Adelbert Rd., Cleveland, OH, E-mail: jonathon .wanta@case.edu

(c) Jonathon W. Wanta and Cecile A. Unger 2017; Published by Mary Ann Liebert, Inc. This is an Open Access article distributed under the terms of the Creative Commons Attribution License, which permits unrestricted use, distribution, and reproduction in any medium, provided the original work is properly cited.
} 
of research to validate such a claim. In fact, there is a lack of research across the board for the transgender community, from surgery and mental health to pediatric and geriatric care. In one review, transgender-specific literature represented just $2.66 \%$ of all lesbian, gay, bisexual, and transgender (LGBT)-related articles. ${ }^{4}$ Compared to all published literature, transgender research represents an even smaller component, creating a crisis in which transgender patient demand and need for services outweigh our knowledge base and level of expertise.

The objective of this article is to describe current themes and trends in medical literature for transgenderspecific care, as well as to identify the knowledge gaps that currently exist to guide future high-quality research to where it is most needed.

\section{Methods}

Search strategy

This was a review of all the literature on transgenderrelated topics published before June 2016. We searched Medline using both medical subject heading (MeSH) terms and keywords in titles and abstracts (TI/AB). The following MeSH terms were included in our search: Transgender Persons, Transsexualism, Sex Reassignment Surgery, Sex Reassignment Procedures, Gender Dysphoria, and Health Services for Transgender Persons. The following keywords were included in our search: transgender, transsexual, gender dysphoria, gender identity disorder, sex reassignment procedure, sex reassignment surgery, genderqueer, gender reassignment, gender confirmation, sex change, intersex, and gender change.

\section{Selection}

From our search, we excluded non-English non-human articles to narrow the literature for our initial review. All remaining articles meeting our search criteria were pulled and abstracts were reviewed for content. Articles were selected for final inclusion only if they were determined to be "trans-centric," that is, focused primarily on transgender-related topics. A summary of the search strategy and selection is depicted in Figure 1.

\section{Analysis}

Abstracts from each article were analyzed for content and study design. Based on overarching themes that emerged, articles were placed in one or more categories according to the primary focus(es) of each article. Articles were also categorized according to article type: primary research article, case report/case series, review, commentary/editorial/letter, practice guidelines, ethics submission, or news article. Year of publication and country of publication were exported from Medline. The impact factor (IF) of the journal in which each article was published was collected from Web of Science's Journal Citation Reports. We present our findings below.

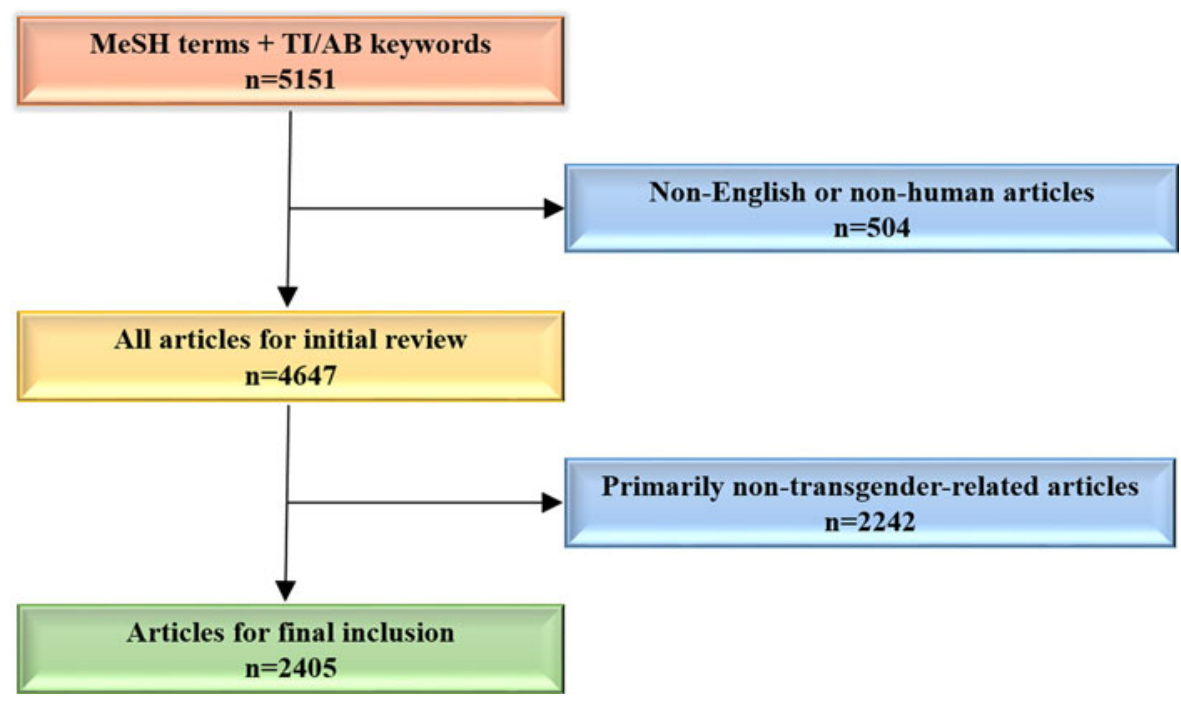

FIG. 1. Graphical depiction of search strategy and selection process. 


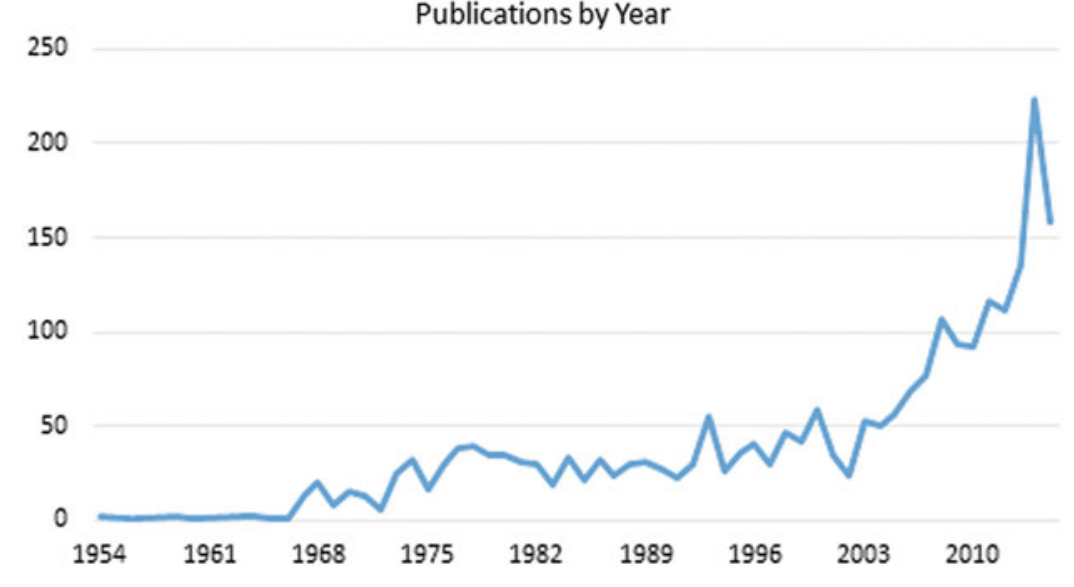

FIG. 2. Total number of trans-centric publications by year.

\section{Results}

A total of 5151 articles were identified for review. Of these, 2405 (52\%) met criteria for inclusion (Fig. 1). Gender, transgender, and transsexual were the most commonly used terms in the article titles reviewed (Supplementary Fig. S1).

The first trans-centric Medline-available article, "Transsexualism and transvestism as psychosomatic and somatopsychic syndromes," was published in 1954 in the American Journal of Psychotherapy. Since this publication date, there has been an exponential increase in publications by year with almost half of all transcentric articles published in the last 10 years (Fig. 2).
To account for the overall increase in total Medlineavailable publications each year, we calculated the number of transgender-specific articles per 100,000 total Medline-available articles published each year (Fig. 3). The relative rate of trans-centric publications compared to all publications has been increasing over the last decade, peaking at 18.6 trans-centric publications per 100,000 total Medline-available publications in 2014.

Articles were published in 629 different journals from 45 different counties. Over $60 \%$ of all articles were published in American journals. The Archives of Sexual Behavior ( $\mathrm{IF}=2.704$ ) leads the field with over $10 \%$ of all published transgender-specific articles $(n=264)$.

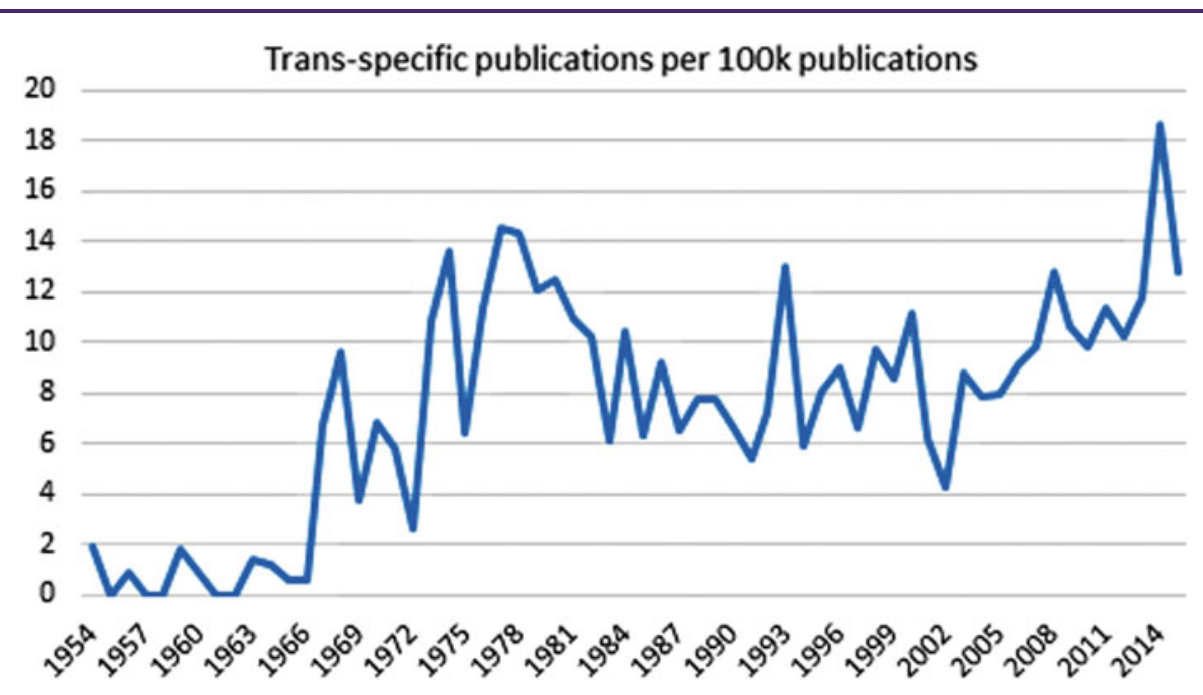

FIG. 3. Trans-specific publications per 100,000 publications each year. 


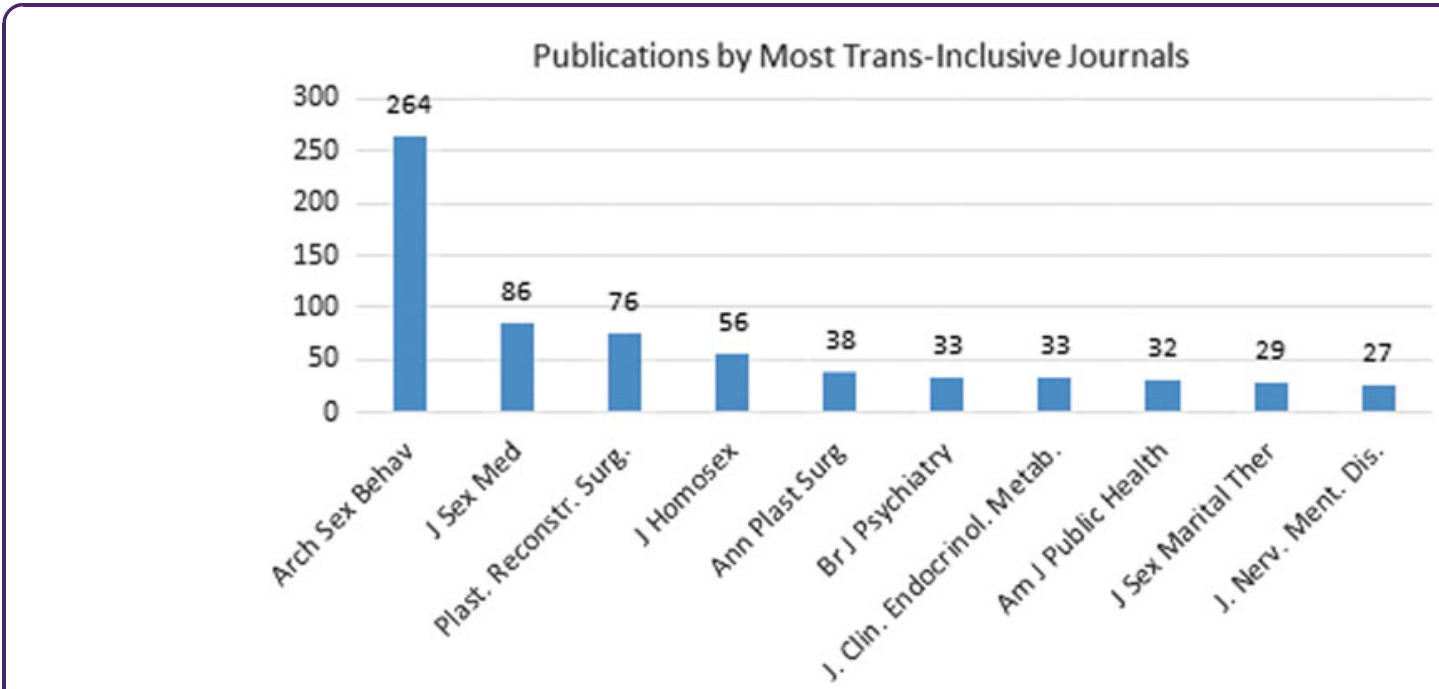

FIG. 4. Top 10 most trans-inclusive journals ranked by number of transgender-specific articles.

This was followed by The Journal of Sexual Medicine $(\mathrm{IF}=2.844)$ with 86 publications and Plastic and Reconstructive Surgery $(\mathrm{IF}=3.087)$ with 76 publications (Fig. 4).

Articles were categorized by the authors on study design. One thousand and ninety-seven (46\%) were primary research articles; 469 (19\%) were commentaries, letters, or editorials; $408(17 \%)$ were case reports or case series; $155(6 \%)$ were review articles; and 53 (2\%) were ethics submissions.

Trans-centric articles published in the four highest impact core medical journals-The New England Journal of Medicine, The Lancet, JAMA: The Journal of the American Medical Association, and The BMJ-make up almost $2 \%$ of the literature with a total of 47 transgender-specific publications. Between 2010 and 2015, publications from

Table 1. Topics by Total Number of Articles and as a Percentage of the $\mathbf{2 4 0 5}$ Trans-Centric Articles

\begin{tabular}{lcc}
\hline Topic & $\begin{array}{c}\text { Total No. of } \\
\text { publications }\end{array}$ & $\begin{array}{r}\text { Percent } \\
\text { of total }\end{array}$ \\
\hline Epidemiology & 46 & 1.9 \\
Surgery & 440 & 18.3 \\
Mental health & 260 & 10.8 \\
Endocrinology and hormones & 297 & 12.3 \\
Cancer & 41 & 1.7 \\
HIV care & 128 & 5.3 \\
Reproduction & 22 & 0.9 \\
Sexuality & 63 & 2.6 \\
Linguistics/voice & 61 & 2.5 \\
Pediatrics & 187 & 7.8 \\
Aging/elderly & 11 & 0.5 \\
Law & 55 & 2.3 \\
Incarceration & 13 & 0.5 \\
Education & 13 & 0.5 \\
Bioethics & 53 & 2.2 \\
\hline
\end{tabular}

these four journals account for just $0.66 \%$ of all Medlineavailable articles, but $2 \%$ of trans-specific articles. On the other hand, only $0.04 \%$ of articles from these four journals over the same time period were transgender specific. In the four highest impact core medical journals, only two articles were primary research articles; the remaining publications consisted of commentaries, case reports, and news articles.

\section{Article content}

Table 1 provides an overview of the number of publications by category. In this section, we present a look at the content, quantity, and quality of the publications in each category.

\section{Epidemiology}

In our search, we identified 46 publications (1.9\% of total) on the epidemiology of transgenderism, all of which were published abroad. The most robust epidemiologic research originated from just six European countries. Articles of lower quality papers were published from Latin American, Asian, and African countries. No comprehensive epidemiologic studies were published on the United States.

\section{Surgery}

Of all articles, 440 (18\%) focused on surgical care with 154 (35\%) dealing with surgical techniques for genderaffirming procedures: $51 \%$ male to female (MTF) surgery and $49 \%$ female to male surgery. Sixteen articles or 3.6\% of all surgical articles focused on revision surgery for patients with complications or unfavorable outcomes after 
their initial surgery, the majority of which were singlepatient case reports. Six percent discussed long-term patient satisfaction and quality of life following surgery. Follow-up more than 1 year after surgery was uncommon among these articles.

\section{Mental health}

Two hundred and sixty articles (11\%) were published in the psychiatry or psychology literature. A common theme was the diagnosis and management of psychiatric comorbidities such as depression, anxiety, substance use, eating disorders, obsessive compulsive disorder, and autism in individuals with concurrent gender dysphoria.

We identified eight articles that investigated the role of the mental health professional with regard to patient access to transition services. There were 53 articles that addressed psychoanalysis or psychotherapy for transgender individuals, by in large, skewed toward earlier dates of publication. Since 1997, there has been debate in the literature on the proper terminology and diagnoses for transgender individuals seeking medical care. At least 15 articles addressed issues pertaining to language used in the Diagnostic and Statistical Manual of Mental Disorders.

\section{Endocrinology and hormones}

We found 297 publications (12\%) on hormone therapy and metabolic outcomes in patients taking cross-sex hormones, including eight randomized clinical trials evaluating the effects of androgens and estrogens in transitioning patients.

One hundred and seventy articles $(57 \%$ of endocrinology-related articles) discussed hormone-related side effects, ranging from cardiovascular and bone (the most commonly discussed side effects) to the immune system and dermatologic effects. Follow-up in these trials was intermediate with most studies evaluating outcomes at 12 or 24 months. Only one long-term analysis followed patients for 10 years for hormone-related side effects. ${ }^{5}$ Conversely, some researchers have investigated all-cause mortality in individuals taking hormones with the most comprehensive published in 2011 with over 1200 participants and a median follow-up of 18.5 years. ${ }^{6}$ There were very few data published on at-risk patient populations such as the elderly and those with pre-existing medical conditions.

\section{Cancer}

In our search, there were 41 published articles (1.7\%) discussing the prevalence of, risk factors for, and treatment of cancers in transgender individuals. The research designs used to study the prevalence of cancer in this patient population are variable with few large studies looking at hormone-sensitive cancers of the breast or prostate.

\section{HIV care}

We know that transgender individuals, especially trans women of color, are at a particularly high risk for HIV. ${ }^{9}$ A disproportionately high percentage of the international trans-centric literature has been focused on HIV, painting a more global picture of the transgender HIV epidemic. ${ }^{10}$ A significant proportion of HIV publications looked at the incidence and treatment of HIV in transgender sex workers, especially in low-income countries.

Fifteen articles analyzed high-risk behaviors, and 14 articles analyzed HIV prevention. While preexposure prophylaxis (PrEP) proves a promising approach for stymieing the spread of HIV, one review finds that trans women have been all but excluded from clinical trials. ${ }^{11}$

\section{Reproduction and sexuality}

In our search, 22 articles $(0.9 \%)$ focused on reproduction and fertility in the transgender patient population. Very few clinical studies have been published, and most articles are found in the bioethics literature.

More research exists on sexuality within the transgender population: 63 articles (2.6\%) addressed sexual orientation and partnering. Since the 1970s, there have been several attempts to classify transgender individuals on the basis of sexual orientation. Newer studies have investigated how transitioning can affect the sexuality of the transgender individual ${ }^{12}$ or his or her partner. ${ }^{13}$

\section{Linguistics/voice}

There are many published articles on linguistics: 61 articles $(2.5 \%)$ have been published on surgical techniques and anatomy, communication therapy, and psychiatric parameters related to voice perception. Literature in this field also accounted for a disproportionately high number of primary research articles when compared to other topics discussed in this review.

\section{Pediatrics}

There were 187 articles (7.8\%) focusing on pediatric patients with incredibly diverse subtopics. The most common theme was dealing with the challenge of puberty in the transgender adolescent. Since the introduction of 
puberty blockers, researchers have debated who should get them, ${ }^{14}$ when they should get them, ${ }^{15}$ who should prescribe them, ${ }^{16}$ and, most recently, who should pay for them. ${ }^{17}$

The Dutch have taken the lead in publishing guidelines for puberty suppression, arguing that withholding treatment and allowing an unwanted puberty to progress is "harmful to well-being." 18,19 Only one study to date has followed transgender youth in whom puberty was suppressed. ${ }^{19}$

Few articles have investigated the persistence of childhood onset of gender dysphoria through puberty and beyond, and only one has investigated factors that may help predict the persistence of gender dysphoria. ${ }^{20}$

\section{Aging/elderly}

Through our search, we identified a total of 11 articles $(0.5 \%)$ that focused on the geriatric transgender population. Very little data exist on the long-term effects of hormone therapy in the aging transgender population, and there are no articles on end-of-life care for transgender individuals.

\section{Law/incarceration}

Fifty-five publications (2.3\%) specifically focused on the intersection of transgender individuals with the law, and 13 articles (0.5\%) investigated transgender care in the prison population. The literature follows the progression of social acceptance over time, and, in some respects, the law had to adapt in response to the progress in the medical field and with gender confirmation surgeries. ${ }^{21}$

\section{Education}

"Education" was a primary focus in just 13 articles $(0.5 \%)$. The majority of these articles focused on increasing trans-inclusiveness as a part of the education of medical, nursing, and pharmacy students. Examples include changes to the curriculum ${ }^{22}$ and a simulated transgender patient encounter. ${ }^{23}$

\section{Bioethics}

Fifty-three articles $(2.2 \%)$ were identified as bioethics publications. These articles consisted primarily of commentaries and editorials focused on the role of the gatekeeper, pediatric patients, and fertility and reproduction as previously discussed. In "Still Quiet After All These Years," Nelson writes, "[T]ransgender issues still do not attract much bioethical attention, and the deeply reflective kind of consideration that I had hoped more of the field would take up remains, by and large, conspicuous by its absence." ${ }^{24}$ While he focuses here on biotechnology and hormonal and surgical interventions, bioethics research can really fit into any of our themes as listed above, but, by in large, is lacking in the literature.

\section{Nursing and social work}

Ninety trans-centric Medline-available articles were published in nursing journals and 11 were published in social work journals, representing $4.2 \%$ of the total publications. Most of these articles are commentaries, letters, editorials, and practice guidelines; very few are primary research articles. At the same time, these articles focused on traditionally underserved, vulnerable, or stigmatized populations in the transgender community such as the elderly, minors, sex workers, or those with HIV.

\section{Discussion}

When we look at the specific topics covered in the literature, we can see the strengths and knowledge gaps that currently exist. We present our assessment of the published literature and discuss areas that may warrant future attention.

\section{Epidemiology}

The epidemiologic studies have suffered from selection bias, especially those published in the United States. These studies have been cross-sectional in nature and have looked at the prevalence of transgenderism in traditionally "LGBT-friendly" parts of the United States such as New York City and San Francisco. Thus, it is difficult to generalize and estimate the prevalence of gender minorities across the United States, necessitating more comprehensive research moving forward. Future research should also aim to identify demographic and social determinants that may influence healthcare, access to care, and outcomes of transitionspecific services.

\section{Surgery}

There were many published articles on surgical technique for gender-affirming procedures. Surgeons performing these procedures should continue to publish on their innovations and describe their outcomes. However, there exists a pressing need to consider secondary outcomes and revision surgeries, which may represent more complex procedures with varying outcomes. In one study, 22\% of MTF patients who had previously undergone a vaginoplasty procedure required a revision 
surgery, ${ }^{25}$ but revision surgeries are grossly underrepresented in the literature. To properly assess revision surgeries, longitudinal follow-up is required, either from the patient's home institution or from outside hospitals.

As surgical options become more accessible to the transgender patient, psychosocial outcomes will be even more important in the decision-making process. As an example, a 2014 article by Weigert et al. evaluated patient body image using a validated scale before and after chest surgery. ${ }^{26}$ This type of prospective and standardized research has been missing from the field, and we urge those performing gender-affirming surgeries to follow psychosocial outcomes in addition to surgical outcomes longitudinally in their patients.

Last, in a continual effort to remain patient centered, we must at times take a step back and evaluate our patients' goals and expectations, especially when it comes to invasive surgical procedures. Just one article from 1993 specifically asked transgender men undergoing phalloplasty what factors of esthetics, function, and psychosocial adjustment were most meaningful to the patient after surgery. ${ }^{27}$ By first identifying our patients' goals, we can tailor our techniques to better maximize areas of most importance. It is paramount, then, that future research explores this question for all other common gender confirmation surgeries as our techniques and patient expectations continually change.

\section{Mental health}

Mental health professionals should be commended on their work in transgender research, as there is a plethora of published articles in this field. However, most published articles are descriptive and very few studied actual risk factors for psychiatric comorbid conditions. For example, Bariola et al. identified demographic and psychosocial factors associated with resilience specific to the transgender community. ${ }^{28}$ In this study, the authors found that higher income, heterosexuality, and frequent contact with LGBT peers were predictive of higher resilience, leading the authors to recommend "tailored mental health interventions and resiliencebuilding programs" for transgender individuals. More research in the same vein is needed to better understand the important determinants that place transgender patients at risk for, protect them against, and cope with psychiatric illness.

Little research has focused on the role of the mental health professional with regard to patient access to transition services. According to the World Professional Association for Transgender Health Standards of
Care, a mental health professional must first evaluate transgender patients seeking hormone therapy or gender confirmation surgery for "medical necessity and readiness." 29 The counterargument to this requirement is that it represents a heteronormative paternalism that is discriminatory in nature, placing undue burden on transgender patients when no such burden would be placed on a cisgender patient seeking a comparable surgery. Selvaggi and Giordano make the case that requiring a letter from a healthcare professional is not discriminatory, but "responsible care" or even "positive discrimination" intended to help transgender individuals in their transition process. ${ }^{30}$ Budge chronicles her experience as the gatekeeper for a transgender patient, arguing that such a process improves outcomes and patient satisfaction. ${ }^{31}$ In practice, many providers and patients prefer an informed consent model for initiating the medical transition with minimal or no input from a mental health professional, but there are no evidencebased practice guidelines for this methodology. Qualitative research designs with focus groups examining patient experiences as well as their psychosocial outcomes and quality of life could provide important data that would augment what we already know about the process of transitioning.

\section{Endocrinology and hormones}

When compared to other fields of study in transgender care, the endocrine literature deserves commendation for investigating outcomes at intermediate followup. However, with a growing population of transgender adolescents and teenagers starting hormone therapy at an early age, it is essential to investigate the long-term effects of cross-sex hormone exposure and the potential risks of long-term use accumulated over multiple years.

We also noted a dearth of research on hormonal therapy for at-risk populations, such as the elderly who may have pre-existing medical conditions that could complicate treatment. With the 2014 changes in Medicare coverage for therapy, the population of elderly transgender individuals undergoing hormone replacement therapy is likely to increase, and we need to better understand the effects hormone therapy may have on these patients.

Furthermore, the endocrinology literature has been proactive in reviewing the transgender literature and setting research priorities. A 2016 special issue in Current Opinions in Endocrinology, Diabetes, \& Obesity addressed research priorities, barriers to care, and methods for future health research in transgender medicine. ${ }^{32-34}$ We would like to see other journals take up 
this model and apply it to their own fields to adequately summarize the current literature and set goals for further investigation.

\section{Cancer}

The research in cancers in transgender individuals has shed light on the importance of "original gender surveillance," the concept that, even after transitioning, certain screenings based on chromosomal sex may be necessary in certain patients. ${ }^{35}$ We do not know, however, if longterm hormone replacement therapy is protective or deleterious for cancer risk. More research is necessary, again pointing to the importance of long-term followup in patients over several years or decades.

\section{HIV care}

There are many published articles and studies on HIV care in sex and gender minority patients. However, there are some important gaps that need to be highlighted. For example, there is little argument over the effectiveness of PrEP for HIV prevention. However, transgender patients have not always been included in research studies evaluating the effectiveness of PrEP. Physicians and researchers must accommodate the unique experiences and challenges of transgender individuals when devising a treatment program or research study instead of attempting to group transgender individuals together with other often disparate populations. ${ }^{9}$

Reproduction and sexuality

Once considered the "price to pay for transitioning," losing fertility following hormonal or surgical intervention no longer precludes the desire or even the ability to reproduce. ${ }^{36}$ In one study, over half of trans men desired to have children, and $37.5 \%$ would have considered freezing their germ cells had this opportunity been presented. ${ }^{37}$ Yet, articles focusing on reproduction and fertility in the transgender population are severely lacking. We need more data on outcomes of fertility before and after hormone replacement therapy, and providers need to be educated about outcomes to properly counsel their patients. Furthermore, there are no data on patient attitudes about their fertility, which, again, is an essential component to the clinical dialogue.

The majority of the "reproductive conversation" thus far has been left to the bioethicists. While fertility preservation before transitioning is scientifically achievable today, the "unconventional outcome" of having a transgender parent may violate social norms and has thus been hotly debated. ${ }^{38}$
Fitting with the growing consensus that sexuality, especially in youths, is fluid, ${ }^{39}$ newer studies have investigated how transitioning can affect the sexuality of the transgender individual ${ }^{12}$ or his or her partner. ${ }^{13}$ This field of research is emerging and should be encouraged as we continue to care for young transgender patients.

\section{Pediatrics}

In 2016, the US National Institutes of Health announced that they would be funding the largest-ever study on transgender youth. ${ }^{40}$ Years overdue, this research is desperately needed to help guide clinicians in the management of our young transgender patients. It is imperative that we develop tools to assist clinicians in identifying pediatric patients who may require closer monitoring or early treatment gender dysphoria versus those with more transient gender dysphoria that is considered a normal stage of healthy development.

In addition, the pediatric transgender patient should be viewed within his or her family unit. In a study of 66 transgender youth, Simons et al. represents found that parental support was protective against psychiatric comorbid conditions. ${ }^{41}$ By identifying protective factors for our patients, we can aim to maximize psychosocial well-being, while minimizing risk factors that may lead to adverse outcomes, behooving future research in this field.

With increased awareness, support, and social acceptance, there is an increasing population of transgender children who have been able to "socially transition" or live as their preferred gender from a young age. A recent article investigated mental health parameters in 73 transgender children allowed to socially transition, finding no difference in depression risk and only a mild elevation in anxiety risk when compared to age-matched controls. ${ }^{42}$ Further research in this emerging field will help to drive early intervention and programs for transgender youth.

\section{Aging/elderly}

We are entirely unprepared to care for our aging transgender population. While elderly transgender individuals certainly share many healthcare needs with their cisgender peers, they also have unique needs that may sometimes get overlooked by healthcare providers. ${ }^{43}$ As previously mentioned, we know very little about the long-term effects of hormone replacement therapy, which directly affects our aging population. We also know very little about the effects of hormone therapy on comorbid conditions that could complicate 
gender-affirming treatment. Finally, we know very little about end-of-life care for transgender individuals. Research needs to be directed in these areas as the transgender population continues to age.

\section{Law/incarceration}

The protection of transgender rights is a public health issue, as violation of these rights can have severe implications on health and healthcare access. ${ }^{44}$ Considering the high prevalence of discrimination and physical assault experienced by transgender people, ${ }^{2}$ more research is warranted concerning the creation and enforcement of laws protecting the rights of transgender individuals.

Several commentaries, letters, and editorials have debated current policies and legal implications, the ethics of providing hormonal therapy, and standards of care for prisoners. One study reports that 55\% of transgender inmates had concerns accessing transgender healthcare and $42 \%$ had been physically or verbally harassed by other inmates, often related to their transgender status. ${ }^{45}$ Despite several rounds of guidelines and ethics discussions in the literature, it is clear that incarcerated transgender individuals pose a unique challenge, necessitating more comprehensive research and direction.

\section{Education}

We applaud efforts to adopt trans-inclusive curriculum changes for medical, nursing, and pharmacy students. However, this sort of bottom-up approach should not be the only approach of improving transgender education in the medical setting. Considering the relative dearth of transgender-specific publications before the early 2000 s, there are likely leagues of medical professionals already in practice that had little formal exposure to transgender care during their training. According to one of our own studies, $80 \%$ of obstetrics and gynecology providers did not receive transgender-specific training during their residency. ${ }^{46}$ This stresses the importance of continuing medical education at all levels, a topic that has thus far been neglected in the literature.

\section{Conclusions}

The purpose of this study was to review the transgender literature for areas needing further research. We categorized 2405 trans-centric articles from Medline based on journal and study design and analyzed them for quality and content.

Since the first publications in the 1950s, there has been a massive shift in ideology and treatment. As a medical community, we have moved from a place where we viewed transgenderism as a mental disorder to a place now where we see it as a variation of normal. While we still have progress to make in education and reducing stigma in healthcare, from a clinical standpoint, the medical field has made great progress in transgender healthcare.

However, from an academic standpoint, the medical field is suffering from a paucity of published data on the care of transgender patients and outcomes related to this care, especially in core medical journals. This is likely a result of a dearth of submissions from physicianresearchers, lack of original research, and an overall lack of high-quality research. Our review demonstrates that most of the published work that exists is not primary research, and there are very few studies that look at longterm outcomes. Even fewer studies are prospective in nature, and only 11 were randomized controlled trials. While we acknowledge that such research design may not always be feasible or ethical, carefully designed studies will ultimately be the driving factor in moving the field toward a more evidence-based model of medicine. This, combined with longer patient follow-up and more prospective trials, will improve our overall quality of research and allow us to better care for our patients.

\section{Acknowledgment}

We would like to thank Jessica DeCaro, MLIS, Cleveland Health Sciences Library, Case Western Reserve University, for her assistance defining our search strategy and for sharing her invaluable insight with utmost patience.

\section{Author Disclosure Statement}

No competing financial interests exist.

\section{References}

1. Steinmetz K. The transgender tipping point. Time. May 29, 2014. http:// time.com/135480/transgender-tipping-point (accessed June 29, 2016).

2. Grant J, Mottet L, Tanis J. Injustice at every turn: a report of the national transgender discrimination survey. Washington, DC: National Center for Transgender Equality and National Gay and Lesbian Task Force, 2011. www.thetaskforce.org/static_html/downloads/reports/reports/ntds_full .pdf (accessed June 16, 2016)

3. Elliott P. Tweaks to North Carolina "Bathroom Bill" unlikely to satisfy critics. Time. 2016. http://time.com/4365202/north-carolina-bathroomtweaks-unlikely-to-satisfy-critics (accessed June 29, 2016).

4. Snyder JE. Trend analysis of medical publications about LGBT persons: 1950-2007. J Homosex. 2011;58:164-188.

5. Wierckx K, Mueller S, Weyers S, et al. Long-term evaluation of cross-sex hormone treatment in transsexual persons. J Sex Med. 2012;9:2641-2651.

6. Asscheman H, Giltay EJ, Megens JAJ, et al. A long-term follow-up study of mortality in transsexuals receiving treatment with cross-sex hormones. Eur J Endocrinol. 2011;164:635-642.

7. Brown GR, Jones KT. Incidence of breast cancer in a cohort of 5,135 transgender veterans. Breast Cancer Res Treat. 2015;149:191-198.

8. Gooren L, Morgentaler A. Prostate cancer incidence in orchidectomised male-to-female transsexual persons treated with oestrogens. Andrologia. 2014;46:1156-1160. 
9. Wilson EC, Chen Y-H, Arayasirikul S, et al. Differential HIV risk for racial/ ethnic minority trans*female youths and socioeconomic disparities in housing, residential stability, and education. Am J Public Health. 2015;105 Suppl 3:e41-e47.

10. Baral SD, Poteat T, Strömdahl S, et al. Worldwide burden of HIV in transgender women: a systematic review and meta-analysis. Lancet Infect Dis. 2013;13:214-222.

11. Escudero DJ, Kerr T, Operario D, et al. Inclusion of trans women in preexposure prophylaxis trials: a review. AIDS Care. 2015;27:637-641.

12. Auer MK, Fuss J, Höhne $\mathrm{N}$, et al. Transgender transitioning and change of self-reported sexual orientation. PloS One. 2014;9:e110016.

13. Theron L, Collier KL. Experiences of female partners of masculineidentifying trans persons. Cult Health Sex. 2013;15 Suppl:62-75.

14. Cohen-Kettenis PT, van Goozen SH. Pubertal delay as an aid in diagnosis and treatment of a transsexual adolescent. Eur Child Adolesc Psychiatry. 1998;7:246-248.

15. Hembree WC. Guidelines for pubertal suspension and gender reassignment for transgender adolescents. Child Adolesc Psychiatr Clin N Am. 2011;20:725-732.

16. Antommaria AHM. Pubertal suppression and professional obligations: may a pediatric endocrinologist refuse to treat an adolescent with gender dysphoria? Am J Bioeth. 2014;14:43-46.

17. Stevens J, Gomez-Lobo V, Pine-Twaddell E. Insurance coverage of puberty blocker therapies for transgender youth. Pediatrics. 2015;136:1029-1031.

18. de Vries ALC, Cohen-Kettenis PT. Clinical management of gender dysphoria in children and adolescents: the Dutch approach. J Homosex. 2012;59:301-320.

19. de Vries ALC, Steensma TD, Doreleijers TAH, Cohen-Kettenis PT. Puberty suppression in adolescents with gender identity disorder: a prospective follow-up study. J Sex Med. 2011;8:2276-2283.

20. Steensma TD, McGuire JK, Kreukels BPC, et al. Factors associated with desistence and persistence of childhood gender dysphoria: a quantitative follow-up study. J Am Acad Child Adolesc Psychiatry. 2013;52:582-590.

21. Belli MM. Transsexual surgery. A new tort? JAMA. 1978;239:2143-2148.

22. Safer JD, Pearce EN. A simple curriculum content change increased medical student comfort with transgender medicine. Endocr Pract. 2013;19:633-637.

23. Greene RE, Garment AR, Avery A, Fullerton C. Transgender history taking through simulation activity. Med Educ. 2014;48:531-532.

24. Nelson JL. Still quiet after all these years: revisiting "the silence of the bioethicists." J Bioeth Inq. 2012;9:249-259.

25. Hage JJ, Goedkoop AY, Karim RB, Kanhai RC. Secondary corrections of the vulva in male-to-female transsexuals. Plast Reconstr Surg. 2000;106:350-359.

26. Weigert R, Frison E, Sessiecq Q, et al. Patient satisfaction with breasts and psychosocial, sexual, and physical well-being after breast augmentation in male-to-female transsexuals. Plast Reconstr Surg. 2013;132:1421-1429.

27. Hage JJ, Bout CA, Bloem JJ, Megens JA. Phalloplasty in female-to-male transsexuals: what do our patients ask for? Ann Plast Surg. 1993;30:323-326.

28. Bariola E, Lyons A, Leonard W, et al. Demographic and psychosocial fac tors associated with psychological distress and resilience among transgender individuals. Am J Public Health. 2015;105:2108-2116.

29. Coleman E, Bockting W, Botzer M, et al. Standards of care for the health of transsexual, transgender, and gender-nonconforming people, version 7 . Int J Transgenderism. 2012;13:165-232.

30. Selvaggi G, Giordano S. The role of mental health professionals in gender reassignment surgeries: unjust discrimination or responsible care? Aesthetic Plast Surg. 2014;38:1177-1183.

31. Budge SL. Psychotherapists as gatekeepers: an evidence-based case study highlighting the role and process of letter writing for transgender clients. Psychotherapy. 2015;52:287-297.

32. Olson-Kennedy J, Cohen-Kettenis PT, Kreukels BPC, et al. Research priorities for gender nonconforming/transgender youth: gender identity development and biopsychosocial outcomes. Curr Opin Endocrinol Diabetes Obes. 2016;23:172-179.

33. Safer JD, Coleman E, Feldman J, et al. Barriers to healthcare for transgender individuals. Curr Opin Endocrinol Diabetes Obes. 2016;23:168-171.

34. Reisner SL, Deutsch MB, Bhasin S, et al. Advancing methods for US transgender health research. Curr Opin Endocrinol Diabetes Obes. 2016;23:198-207.

35. Urban RR, Teng NNH, Kapp DS. Gynecologic malignancies in female-tomale transgender patients: the need of original gender surveillance. Am J Obstet Gynecol. 2011;204:e9-e12.
36. T'Sjoen G, Van Caenegem E, Wierckx K. Transgenderism and reproduction. Curr Opin Endocrinol Diabetes Obes. 2013;20:575-579.

37. Wierckx K, Van Caenegem E, Pennings G, et al. Reproductive wish in transsexual men. Hum Reprod. 2012;27:483-487.

38. Murphy TF. The ethics of fertility preservation in transgender body modifications. J Bioeth Inq. 2012;9:311-316.

39. Bosse JD, Chiodo L. It's complicated: gender and sexual orientation identity in LGBTQ youth. J Clin Nurs. 2016;25:23-24.

40. Reardon S. Largest ever study of transgender teenagers set to kick off. Nature. 2016;531:560.

41. Simons L, Schrager SM, Clark LF, et al. Parental support and mental health among transgender adolescents. J Adolesc Health. 2013;53:791-793.

42. Olson KR, Durwood L, DeMeules M, McLaughlin KA. Mental health of transgender children who are supported in their identities. Pediatrics. 2016;137:e20153223.

43. Persson DI. Unique challenges of transgender aging: implications from the literature. J Gerontol Soc Work. 2009;52:633-646.

44. Reisner SL, Hughto JMW, Dunham EE, et al. Legal protections in public accommodations settings: a critical public health issue for transgender and gender-nonconforming people. Milbank Q. 2015;93:484-515.

45. Brown GR. Qualitative analysis of transgender inmates' correspondence: implications for departments of correction. J Correct Health Care. 2014;20:334-342.

46. Unger CA. Care of the transgender patient: a survey of gynecologists' current knowledge and practice. J Womens Health (Larchmt). 2015;24:114-118.

\section{Abbreviations Used \\ $\mathrm{IF}=$ impact factor \\ $\mathrm{MTF}=$ male to female \\ PrEP $=$ pre-exposure prophylaxis \\ LGBT = lesbian, gay, bisexual, transgender \\ $\mathrm{MeSH}=$ medical subject heading}

Cite this article as: Wanta JW, Unger CA (2017) Review of the transgender literature: where do we go from here? Transgender Health 2:1, 119-128, DOI: 10.1089/trgh.2017.0004.

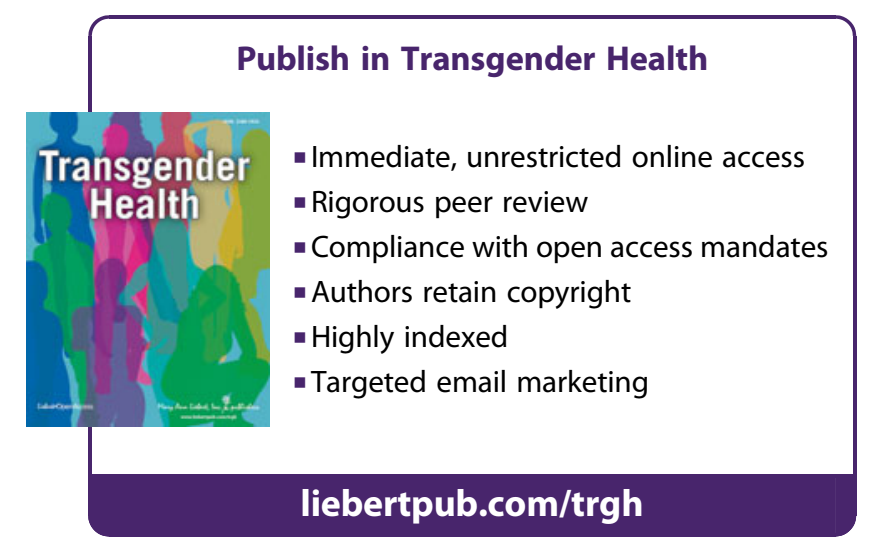

